ARTICLE

Received 13 Jun 2016 | Accepted 18 Jul 2016 | Published 26 Aug 2016

\title{
Hypersensitivity to DNA damage in antephase as a safeguard for genome stability
}

Femke M. Feringa ${ }^{1, *}$, Lenno Krenning ${ }^{1,2, \star}$, André Koch ${ }^{1}$, Jeroen van den Berg ${ }^{1}$, Bram van den Broek ${ }^{1}$, Kees Jalink ${ }^{1}$ \& René H. Medema'

Activation of the DNA-damage response can lead to the induction of an arrest at various stages in the cell cycle. These arrests are reversible in nature, unless the damage is too excessive. Here we find that checkpoint reversibility is lost in cells that are in very late G2, but not yet fully committed to enter mitosis (antephase). We show that antephase cells exit the cell cycle and enter senescence at levels of DNA damage that induce a reversible arrest in early G2. We show that checkpoint reversibility critically depends on the presence of the APC/C inhibitor Emi1, which is degraded just before mitosis. Importantly, ablation of the cell cycle withdrawal mechanism in antephase promotes cell division in the presence of broken chromosomes. Thus, our data uncover a novel, but irreversible, DNA-damage response in antephase that is required to prevent the propagation of DNA damage during cell division.

\footnotetext{
${ }^{1}$ Division of Cell Biology I and Cancer Genomics Center, The Netherlands Cancer Institute, Plesmanlaan 121, Amsterdam 1066 CX, The Netherlands

2 Hubrecht Institute, The Royal Netherlands Academy of Arts and Sciences (KNAW) and University Medical Center Utrecht, Utrecht 3584CT, The Netherlands. ${ }^{*}$ These authors contributed equally to this work. Correspondence and requests for materials should be addressed to R.H.M.

(email: r.medema@nki.nl)
} 
T o protect their genome, cells depend on the action of DNA-damage checkpoints that ensure the detection and repair of DNA damage ${ }^{1,2}$. These checkpoints can induce a reversible arrest at different stages of the cell cycle to allow for repair to take place before the cell divides ${ }^{3,4}$. Functionality of these checkpoints requires accurate coordination between repair, checkpoint signalling and cell cycle progression, such that re-entry into the cell cycle is only allowed once repair has been completed. This is particularly important in G2 phase, since mitotic entry with broken chromosomes poses a direct threat to proper chromosome segregation and genome stability ${ }^{5,6}$. In fact, excessive DNA damage in G2 phase can lead to a p53- and p21-dependent exit from the cell cycle, resulting in an irreversible $\mathrm{G} 2$ arrest $^{5,7-9}$. This way, cell division is prevented if the damage is too severe.

But what happens if a DNA lesion arises after a cell has passed the G2 DNA-damage checkpoint? Several lines of evidence indicate that mitotic cells are refractory to DNA damage, and fail to mount a DNA-damage-induced cell cycle arrest that can prevent cell division ${ }^{10-12}$, and as such damage in mitosis is likely to result in mutated daughter cells.

Contrary to the current view, we show here that the DNA-damage response becomes irreversible already at low levels of DNA damage in late G2. We show that the scheduled loss of early mitotic inhibitor-1 (Emi1) at the end of G2 phase results in hypersensitivity to DNA damage. We find that this novel response to DNA damage is restricted to cells that have separated their centrosomes and display elevated levels of histone H3 Ser10 phosphorylation and Cdk1-dependent phosphorylation. Therefore, we refer to them as cells in antephase. While cells in antephase have been shown to display a reversible arrest in response to various stresses ${ }^{13,14}$, we now uncover a novel mechanism that ensures irreversible removal from the cell cycle, when DNA damage occurs at the brink of mitosis. Importantly, this mechanism is crucial to prevent the propagation of damaged chromosomes to G1 daughter cells and to protect genome stability.

\section{Results}

Cells in antephase show a unique response to DNA damage. To investigate the fate of cells that encountered DNA damage at distinct stages in G2 phase, we performed time-lapse microscopy of untransformed RPE-1 cells with endogenously tagged Cyclin $\mathrm{B} 1^{\mathrm{YFP}}$ (ref. 15). Cyclin B1 expression rises as cells progress through G2 into M, and the absolute level of fluorescence in these cells can be used to derive temporal information, regarding the cell cycle position of the individual cell ${ }^{16}$. Using various doses of ionizing radiation (IR), we find that the subset of Cyclin $\mathrm{B} 1^{\mathrm{YFP}}$-positive cells that recovers from the damage and enters mitosis decreases with increasing dose (Fig. 1a,b). As the dose increases, the recovering fraction is replaced by cells, in which Cyclin B1 translocates to the nucleus (Fig. 1a,c), a process we and others have previously shown to lead to the induction of senescence ${ }^{7,9,17}$. Interestingly, we find that a subset of Cyclin $\mathrm{B} 1^{\mathrm{YFP}}$-positive cells displays a distinct behaviour. This subset directly degrades Cyclin B1 expression in response to DNA damage (Fig. 1a,d), lacking the prior translocation of Cyclin B1 to the nucleus. The fraction of cells that directly loses Cyclin B1 does not increase with increasing doses of IR (Fig. 1d), in sharp contrast to the dose-dependent nuclear Cyclin B1 retention (Fig. 1c). Moreover, we always observe a small percentage of the undamaged Cyclin $\mathrm{B}^{\mathrm{YFP}}$-positive cells that loses Cyclin B1 spontaneously. Remarkably, the cells that directly lose Cyclin B1 have significantly higher levels of Cyclin $\mathrm{B} 1{ }^{\mathrm{YFP}}$ at the moment of irradiation (Fig. $1 \mathrm{e}-\mathrm{g}$ ). In contrast, cells that recover from the damaging event, as well as the cells that translocate Cyclin B1 to the nucleus, express lower levels of Cyclin $\mathrm{B} 1{ }^{\mathrm{YFP}}$ at the moment of irradiation, suggesting that these cells are in the earlier stages of G2 phase (Fig. 1e-g). To further define the cells that directly lose Cyclin B1, we analysed if in this population centrosomes had separated at the moment of irradiation. Strikingly, the vast majority of cells within this population had already started to separate their centrosomes at the time of irradiation, which is normally visible in cells shortly before mitosis (Fig. 1h; Supplementary Fig. 1a). Centrosome separation coincides with a significant increase in levels of phosphorylated H3 (Ser10) and MPM2, both of which are characteristic markers for the onset of mitosis (Fig. 1i,j; Supplementary Fig. 1b). This implies that direct loss of Cyclin B1 upon irradiation is restricted to late G2 or early-prophase cells. We could not observe clear signs of chromosome condensation by 4,6-diamidino-2-phenylindole (DAPI) staining in this population (Supplementary Fig. 1b), most consistent with a cell cycle stage that was previously termed as antephase ${ }^{13,14}$.

Subsequently, we tested the consequence of this unique response for the fate of a cell exposed to low-dose irradiation. We used time-lapse imaging to track Cyclin $\mathrm{B}^{\mathrm{YFP}}$-positive cells that did or did not already separate their centrosomes at the time of irradiation. We found a clear difference in the fraction of Cyclin $\mathrm{B}^{\mathrm{YFP}}$-positive cells without separated centrosomes that managed to recover, when compared with the Cyclin $\mathrm{B}^{\mathrm{YFP}}$-positive cells that had already separated their centrosomes (Fig. 1k), indicating the capacity to recover is compromised in antephase. We confirmed that the hypersensitive DNA-damage response in antephase cells is not due to a difference in overall damage or repair signalling, as DNA-damage foci are formed and resolved at similar kinetics in G2 cells that translocate Cyclin B1 to the nucleus, compared with cells that lose Cyclin B1 directly upon irradiation (Supplementary Fig. 1c). Time-lapse imaging of human dermal microvascular endothelium (HMEC-1), mammary gland epithelial (MCF-10a) and human osteosarcoma (U2OS) cells with endogenously tagged Cyclin $\mathrm{B}^{\mathrm{YFP}}$ revealed that hypersensitivity to DNA damage in antephase is conserved throughout various cell types (Supplementary Fig. 1d). We therefore conclude that cell fate after DNA damage is regulated in a unique way in antephase cells, which is intrinsically different from the known G2 response. Importantly, this response causes cells in antephase to be highly sensitive to DNA damage.

DNA damage causes rapid $\mathrm{APC} / \mathrm{C}^{\mathrm{Cdh} 1}$ activation in antephase. Excessive DNA damage results in activation of the Anaphasepromoting complex/Cyclosome together with its co-factor Cdh1 $\left(\mathrm{APC} / \mathrm{C}^{\mathrm{Cdh} 1}\right)$ in $\mathrm{G} 2$ phase, to promote the degradation of multiple G2/M targets, including Cyclin B1 (refs 7-9,18-21). This activation of APC/C $\mathrm{C}^{\mathrm{Cdh} 1}$ normally occurs several hours after the damage, much later than the onset of Cyclin B1 degradation that we observe in antephase cells. Nevertheless, we set out to test if the direct loss of Cyclin B1 observed after DNA damage in antephase was also caused by APC/C ${ }^{\text {Cdh1 }}$-dependent degradation. Cells in antephase were selected based on the $25 \%$ highest Cyclin B1-expressing cells, which corresponded well with the distinction based on centrosome separation (Supplementary Fig. 2a). Indeed, we could effectively prevent the Cyclin B1 degradation in these cells by depletion of Cdh1 (Fig. 2a). This effect was not seen after depletion of Cdc20, the other co-activator of the APC/C (Fig. 2a; Supplementary Fig. 2b). In addition, we find that the loss of Cyclin B1 is prevented when irradiated antephase cells are treated with the proteasome inhibitor MG-132 (Supplementary Fig. 2c). Immunofluorescent staining of the APC/C targets Aurora A, Cyclin A2 and Plk1 shows that these proteins are also degraded in cells that lost Cyclin B1 
a

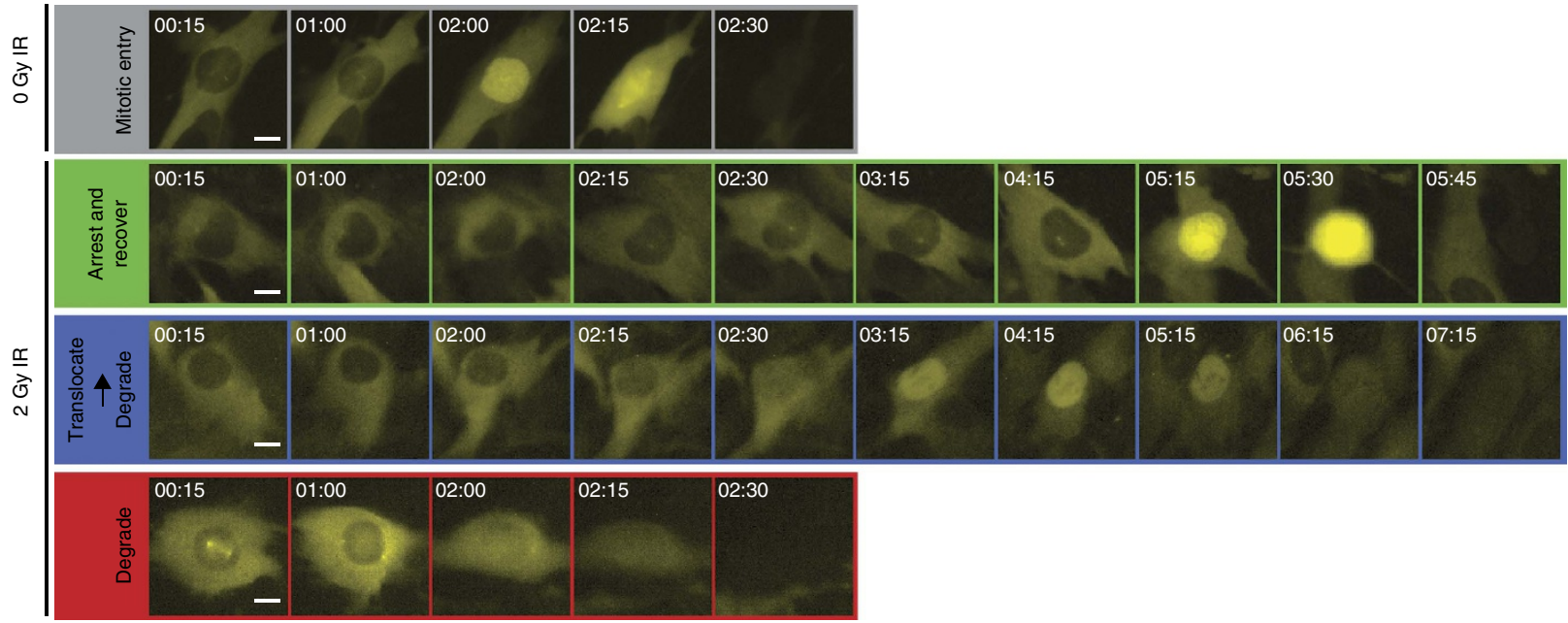

b

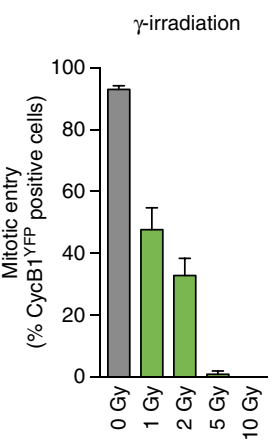

c

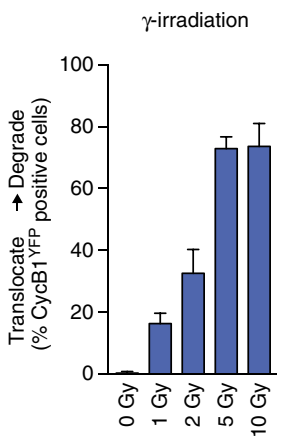

d

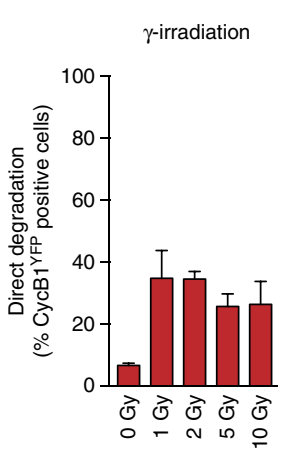

e

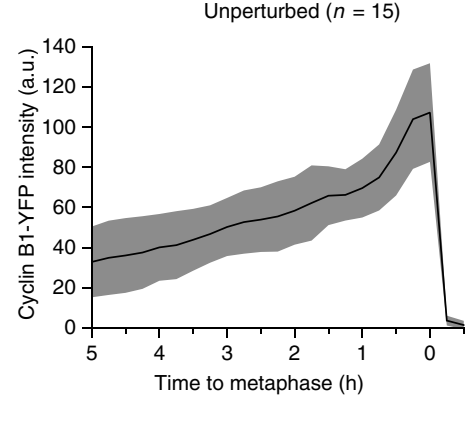

f

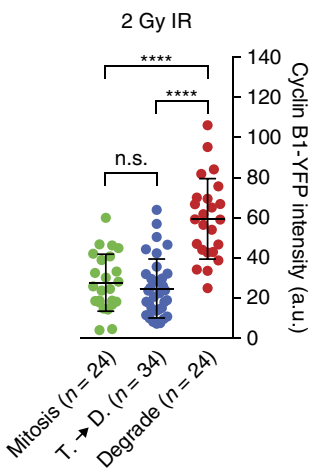

g

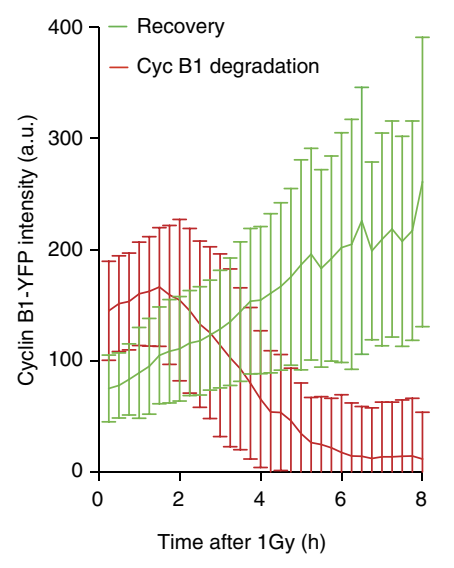

h

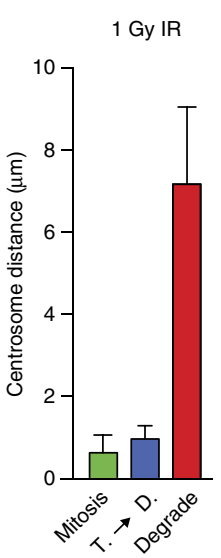

i

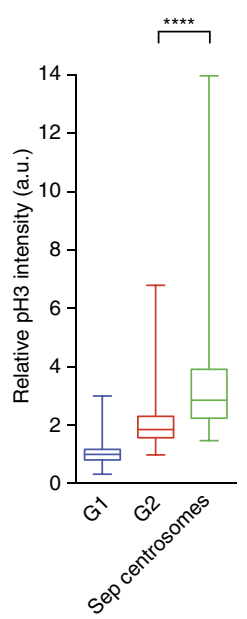

j

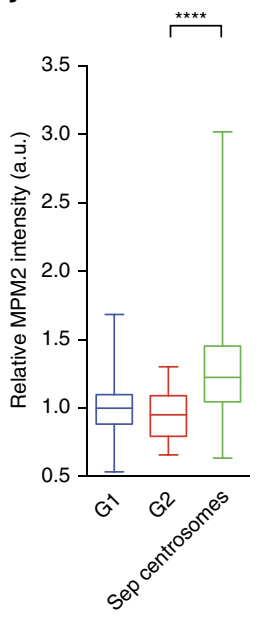

k

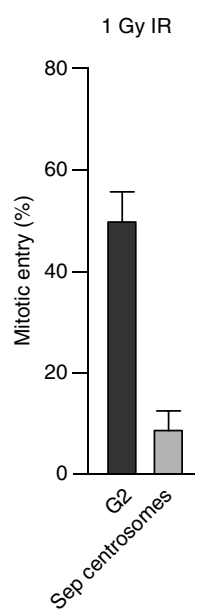

Figure 1 | Cells in antephase show a unique response to DNA damage. (a) Time-lapse images represent distinct responses of RPE CCNB ${ }^{Y F P}$-postive cells to ionizing radiation (IR). Time, hh:mm. Scale bars, $10 \mu \mathrm{m}$. (b-d) Quantification of the frequency with which the responses in a are observed in Cyclin B1 ${ }^{\mathrm{FFP}}$ positive cells within $16 \mathrm{~h}$ after IR. Mean \pm s.d. of three independent experiments. (e) Cyclin B1 ${ }^{\mathrm{YFP}}$ intensity during unperturbed G2/M progression in individual cells, and in silico aligned at metaphase. Mean \pm s.d., $n=15$ RPE CCNB YFP cells from one experiment. (f) Cyclin B1 ${ }^{\text {YFP }}$ intensity measured 15 min after 2 Gy IR in cells undergoing the indicated responses. Dots represent individual cells ( $n)$, mean \pm s.d., results are representative of three independent experiments. ${ }^{\star \star \star \star} P<0.0001$ (unpaired $t$-test). (g) Cyclin B1 ${ }^{\mathrm{YFP}}$ levels measured in individual cells that either recovered from $1 \mathrm{~Gy} I \mathrm{R}$ and entered mitosis or that lost Cyclin B1 completely. Mean \pm s.d. $n=15$ (recovery) and $n=19$ (degradation) RPE CCNB ${ }^{\text {YFP }}$ cells. (h) Centrosome distance measured 15 min after $1 \mathrm{~Gy} I \mathrm{R}$ in cells undergoing the indicated responses. Mean \pm s.e.m. of three independent experiments. (i,j) RPE CCNB ${ }^{\mathrm{YFP}}$ cells were tracked $5 \mathrm{~h}$ by live-cell imaging followed by fixation and staining for MPM2 or pH3. G1, G2 and Cyclin B1-positive cells with separated centrosomes were differentiated based on the live-cell imaging data. Box plots represent $n>40$ cells per condition pooled from three independent experiments. (k) Spontaneous recovery after $1 \mathrm{~Gy}$ in indicated cell types. Cyclin B1 $1^{\mathrm{YFP}}$-positive cells were separated in two populations based on centrosome status. Mean \pm s.e.m. of three independent experiments. 

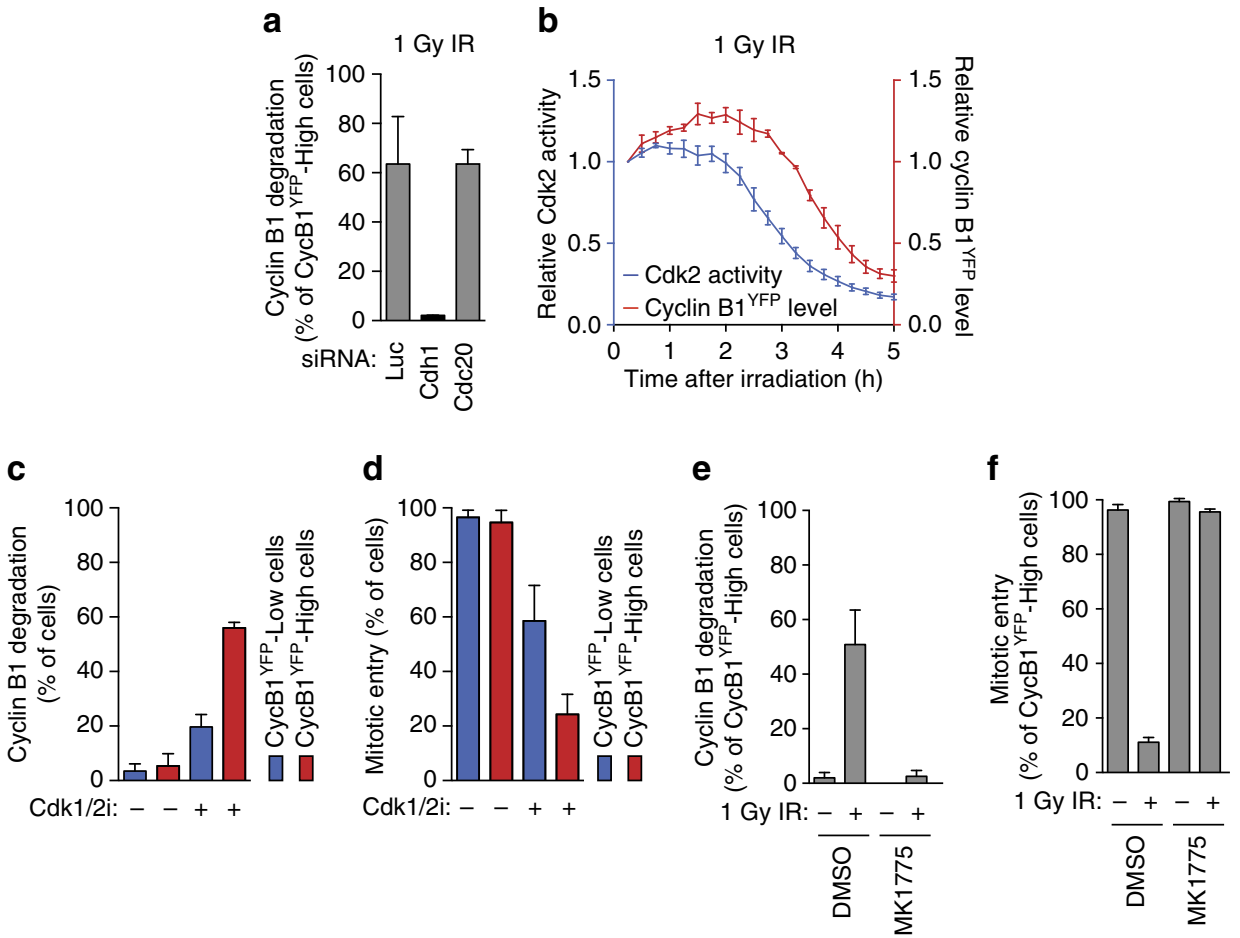

Figure 2 | DNA damage causes rapid APC/C $\mathbf{C}^{\mathbf{C d h} 1}$ activation in antephase. (a) Direct degradation of Cyclin B1 in antephase cells depleted for luciferase, Cdh1 or Cdc20 that were irradiated with $1 \mathrm{~Gy}$. Antephase cells were selected based on top $25 \%$ Cyclin B1 $1^{\mathrm{YFP}}$-expressing cells, measured 15 min after IR. Mean \pm s.d. of two independent experiments. (b) Relative Cdk2 activity and Cyclin B1 ${ }^{\text {YFP }}$ intensity were measured in individual antephase cells that degraded Cyclin B1 after 1 Gy IR. All time points were normalized to Cdk2 activity and Cyclin B1 level at the first frame, which were set to one. Mean \pm s.e.m. of three independent experiments. (c,d) Cyclin B1 degradation (c) and mitotic entry (d) scored in undamaged G2 and antephase cells within $10 \mathrm{~h}$ after wash out of Cdk1 (RO-3306) and Cdk2 (Roscovitine) inhibitors that had been present for $5 \mathrm{~h} . \mathrm{G} 2$ and antephase cells were separated based on $75 \%$ lowest and $25 \%$ highest $\mathrm{Cyclin} B 1^{\mathrm{YFP}}$-expressing cells. Mean \pm s.e.m. of three independent experiments. (e,f) Cyclin B1 degradation (e) and mitotic entry (f) scored in antephase cells (selected as in Fig. 2a) within $10 \mathrm{~h}$ after IR 1 Gy. Wee1 inhibitor (MK 1775) or dimethylsulfoxide were added immediately after IR.

Mean \pm s.d. of three independent experiments.

(Supplementary Fig. 2d,e). Collectively, these results show that the loss of Cyclin B1 following DNA damage in antephase results from general activation of the $\mathrm{APC} / \mathrm{C}^{\mathrm{Cdh} 1}$.

Next, we aimed to find out how $\mathrm{APC} / \mathrm{C}^{\mathrm{Cdh} 1}$ can be activated specifically in antephase cells in response to a low-dose irradiation. Activation of $\mathrm{APC} / \mathrm{C}^{\mathrm{Cdh} 1}$ in undamaged cells normally occurs in anaphase, following the loss of Cdk activity ${ }^{22}$. Therefore, we investigated whether Cdk inhibition induced by DNA damage precedes the onset of the $\mathrm{APC} / \mathrm{C}^{\mathrm{Cdh} 1}$ activation in cells in antephase. Using a previously described live-cell sensor for Cdk2 activity ${ }^{23}$, we measured Cdk2 activity and Cyclin B1 levels in single cells after irradiation (Supplementary Fig. 2f). A clear drop in Cdk2 activity precedes Cyclin B1 degradation in antephase cells irradiated with 1 Gy (Fig. 2b). Next, we tested whether the inhibition of Cdk1 and/or Cdk2 activity by itself would be sufficient to cause $\mathrm{APC} / \mathrm{C}^{\mathrm{Cdh}} 1$ activation in late G2. Live-cell imaging of cells in antephase treated with Cdk1 and/or Cdk2 inhibitors revealed that only dual inhibition effectively induced the direct degradation of Cyclin B1, implying that Cdk1 or Cdk2 activity alone is sufficient to keep APC/C Cdh1 inactive at the end of G2 phase (Supplementary Fig. 2g,h). More importantly, temporary inhibition of Cdk1 and Cdk2 activity was enough to induce the Cyclin B1 degradation in undamaged cells in antephase, but did not affect early G2 cells in the same way. Instead, G2 cells halted progression to mitosis, but as expected, the majority continued cell cycle progression after they were released from Cdk1/2 inhibition (Fig. 2d; Supplementary Fig. 2i). In contrast, the antephase cells degraded Cyclin B1 and were not able to enter mitosis after wash out of both inhibitors (Fig. 2c,d; Supplementary Fig. 2i). This shows that mere inhibition of Cdk activity in cells that are at the end of G2 phase is sufficient to activate $\mathrm{APC} / \mathrm{C}^{\mathrm{Cdh} 1}$. Conversely, inhibition of Weel, the kinase responsible for inhibitory phosphorylation of Cdk subunits ${ }^{24}$, almost completely prevented the DNA-damage-induced degradation of Cyclin B1 in antephase and promoted mitotic entry (Fig. 2e,f; Supplementary Fig. 2j). Thus, abrupt Cdk inhibition induced by the activation of the DNA-damage checkpoint in antephase causes premature $\mathrm{APC} / \mathrm{C}^{\mathrm{Cdh} 1}$ activation, resulting in degradation of Cyclin B1 and cell cycle exit.

Emi1 acts to maintain recovery competence in G2 cells. While our data clearly shows that loss of Cdk activity in antephase causes $\mathrm{APC} / \mathrm{C}^{\mathrm{Cdh} 1}$ activation, treatment with $\mathrm{Cdk} 1 / 2$ inhibitors does not activate $\mathrm{APC} / \mathrm{C}^{\mathrm{Cdh} 1}$ in all G2 cells. This implies that early G2 cells are protected from a rapid cell cycle exit upon stress-induced Cdk inhibition. A well-known antagonist of APC/C Cdh1 activity in S and G2 phase is Emil (refs 25,26). Emil is degraded in prophase, prior to nuclear envelope breakdown as a consequence of Plk1- and Cdk1-dependent phosphorylation of Emil (refs 27-31). Excessive DNA damage in G2 cells can cause p21-dependent downregulation of Emil resulting in the $\mathrm{APC} / \mathrm{C}^{\mathrm{Cdh} 1}$ activation and degradation of its targets ${ }^{19,20}$. However, the latter response is limited to cells that contain high levels of damage, and follows only after p21-dependent nuclear retention of Cyclin B1-Cdk complexes ${ }^{7,9}$, not matching the fast response we observe in antephase cells. Therefore, we set 
out to test if Emil is needed to protect G2 cells from APC/C $\mathrm{C}^{\mathrm{Cdh} 1}$ activation by DNA damage. Using drug-free synchronized RPE-1 Fucci cells (Supplementary Fig. 3a-c), we determined the timing of Emi1 degradation in RPE-1 cells. Staining for Cyclin A2, Cyclin B1 and Emil on western blot revealed that Emil is indeed degraded before the Cyclins (Fig. 3a). Since, Cyclin A degradation occurs directly after nuclear envelope breakdown ${ }^{32-35}$, this is most consistent with the degradation of Emil shortly before mitosis, similar to previous observations ${ }^{27-31}$. Thus, DNAdamage-induced activation of $\mathrm{APC} / \mathrm{C}^{\mathrm{Cdh} 1}$ in antephase may be a consequence of limited Cdk activity in cells that have already lost Emil, and are therefore unable to prevent the APC/C Cdh1 activation. To corroborate this notion, we tested whether Plk1-dependent degradation of Emil is indeed needed for the unique DNA-damage response we find in antephase cells. Inhibition of Plk1 activity a few hours before irradiation resulted in a clear reduction in direct degradation of Cyclin B1 in antephase cells following DNA damage. This indicates that the scheduled loss of Emil at the end of G2 phase is required for the antephase response to DNA damage (Fig. 3b,c). Next, we asked if reduction of Emil expression could render the checkpoint irreversible throughout G2. Since, depletion of Emil leads to marked phenotypes like rereplication ${ }^{36,37}$, we titrated down the concentration of short interfering RNA (siRNA) against Emil to establish conditions for depletion of Emil that would not perturb cell division in non-damaged cells (Supplementary Fig. 3d,e). Interestingly, partial Emil depletion, which hardly affects cell cycle progression in undamaged cells (Supplementary Fig. 3d,e; Supplementary Methods), leads to a very apparent hypersensitivity to DNA damage in G2 (Fig. 3d,e; Supplementary Fig. 3f). The majority of control G2 cells are able to recover from
1 Gy of irradiation, whereas $>80 \%$ of the Emil-reduced cells degrade Cyclin B1 at this dose of irradiation, preventing their recovery (Fig. 3d,e; Supplementary Fig. 3f). In addition, reduction of Emi1 in undamaged cells allows the direct Cyclin B1 degradation in all G2 cells, when Cdk activity is chemically inhibited (Fig. 3f; Supplementary Fig. 3g). Conversely, overexpression of Emil completely prevents the direct DNAdamage-induced degradation of Cyclin B1 in antephase cells (Fig. 3g). Thus, our data shows that Emil acts to sustain checkpoint reversibility in G2, and its degradation at the end of G2 phase results in an irreversible DNA-damage response that ensures a rapid cell cycle exit, even at low levels of DNA damage.

Hypersensitivity in antephase protects genome stability. Our observation that cells in antephase directly degrade Cyclin B1 after low doses of irradiation indicates that antephase cells withdraw from the cell cycle in the presence of low levels of DNA damage. Indeed, none of the cells in antephase that degraded Cyclin B1 after exposure to $1 \mathrm{~Gy}$ were able to proliferate within $72 \mathrm{~h}$ after damage (Fig. $4 \mathrm{a}, \mathrm{b}$ ). In contrast, $75 \%$ of the G2 cells that recovered from this dose also progressed into subsequent cell divisions within $72 \mathrm{~h}$ (Fig. 4a,b). Moreover, time-lapse analysis of individual cells that were followed for 5 days and subsequently stained for senescence-associated $\beta$-galactosidase (SA- $\beta$-gal) activity, confirmed that antephase cells enter a senescent state in response to a low-dose irradiation (Fig. 4c).

While high doses of irradiation lead to extensive checkpoint activation, including long-lasting Cdk inhibition, and high levels of p53 and p21, low doses of irradiation induce a much milder checkpoint response only temporarily inhibiting Cdk activity ${ }^{7}$.

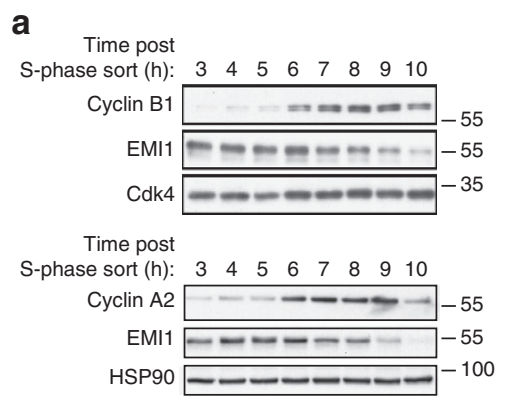

d

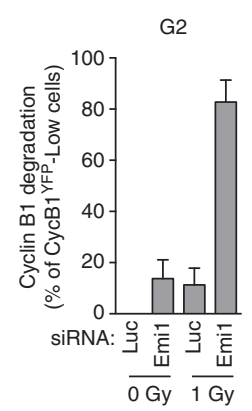

e

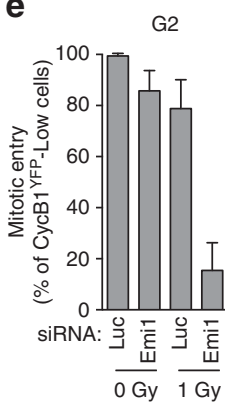

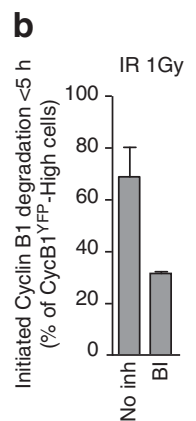

C

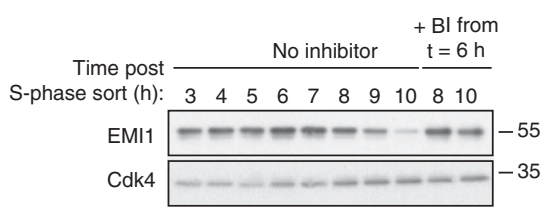

$\mathbf{f}$

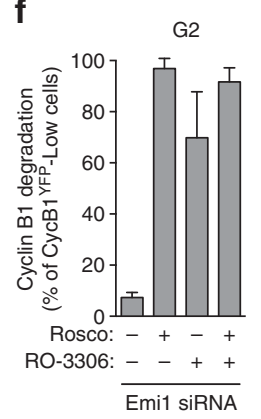

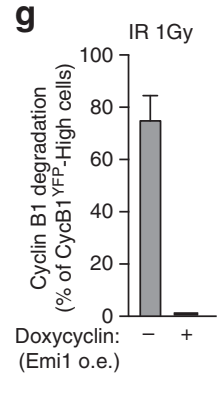

Figure 3 | Emi1 acts to maintain recovery competence in $\mathbf{G 2}$ cells. (a). Western blot showing EMI1, Cyclin A2 and Cyclin B1 protein levels at the indicated time following early-S phase sort. Representative blots of two independent experiments are shown. (b) Quantification of antephase cells (selected as in Fig. 2a) that started direct Cyclin B1 degradation within $5 \mathrm{~h}$ from IR $1 \mathrm{~Gy}$. BI was added 2,5 h before IR. Mean \pm s.e.m. of three independent experiments. (c) Western blot showing Emi1 protein levels following early-S phase sort in the absence or presence of BI from $6 \mathrm{~h}$ after the sort. (d,e) Cyclin B1 degradation (d) and mitotic entry (e) within $10 \mathrm{~h}$ after $1 \mathrm{~Gy}$ IR was analysed in RPE CCNB YFP G2 cells (selected as in Fig. 2c) partially depleted for EMI1. Mean \pm s.d. of three independent experiments. (f) Cdk1 (RO-3306), Cdk2 (Roscovitine) or both were inhibited in undamaged RPE CCNB YFP cells partially depleted of EMI1. Direct Cyclin B1 degradation of cells in G2 phase at the moment of Cdk inhibition was analysed. Mean \pm s.d. of three independent experiments. (g) EMI1 Turq overexpression was induced in RPE CCNB ${ }^{\text {YFP }}$ cells $2 \mathrm{~h}$ before IR $1 \mathrm{~Gy}$ using doxycycline. Direct Cyclin B1 degradation was scored in antephase cells (selected as in Fig. 2a). Mean \pm s.e.m. of three independent experiments. 
a

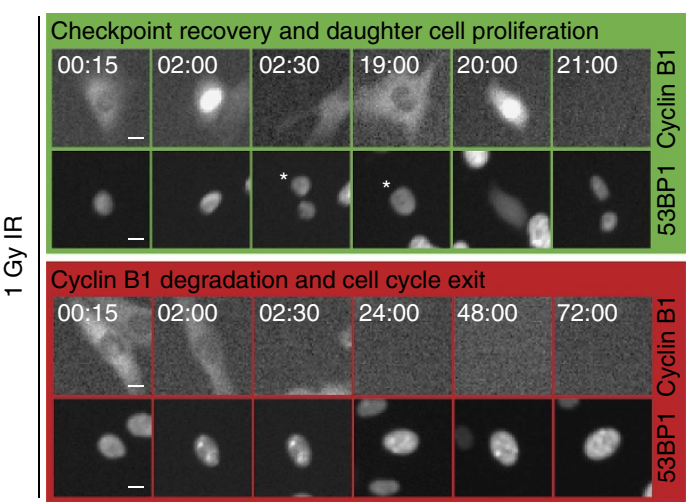

d

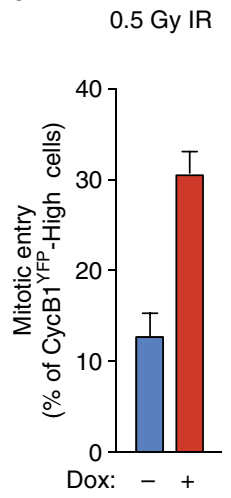

e

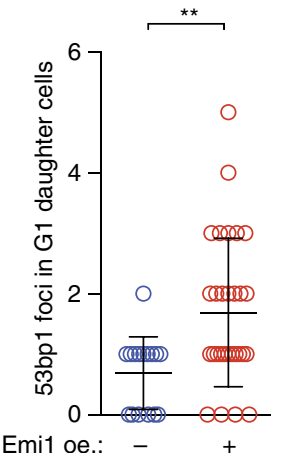

b

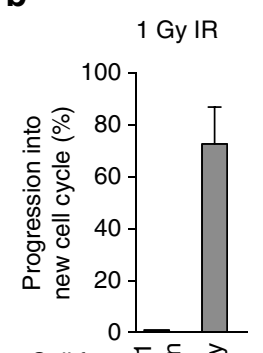

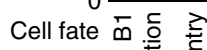
after 1 Gy: $\subseteq$

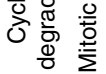

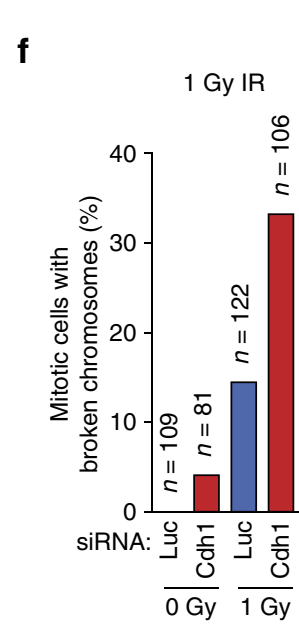

c

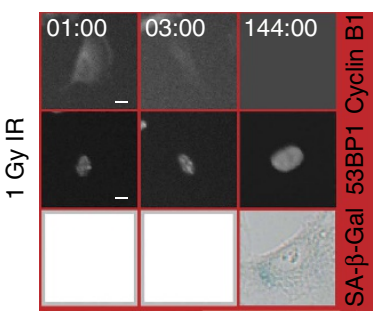

g

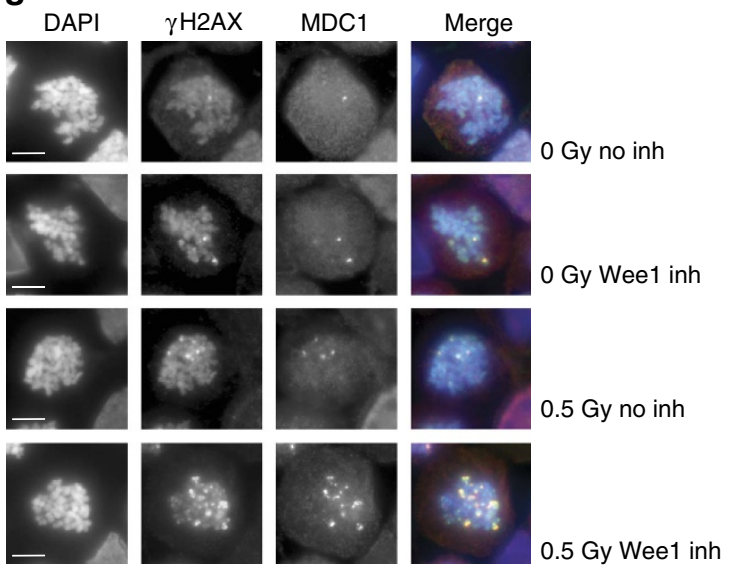

h
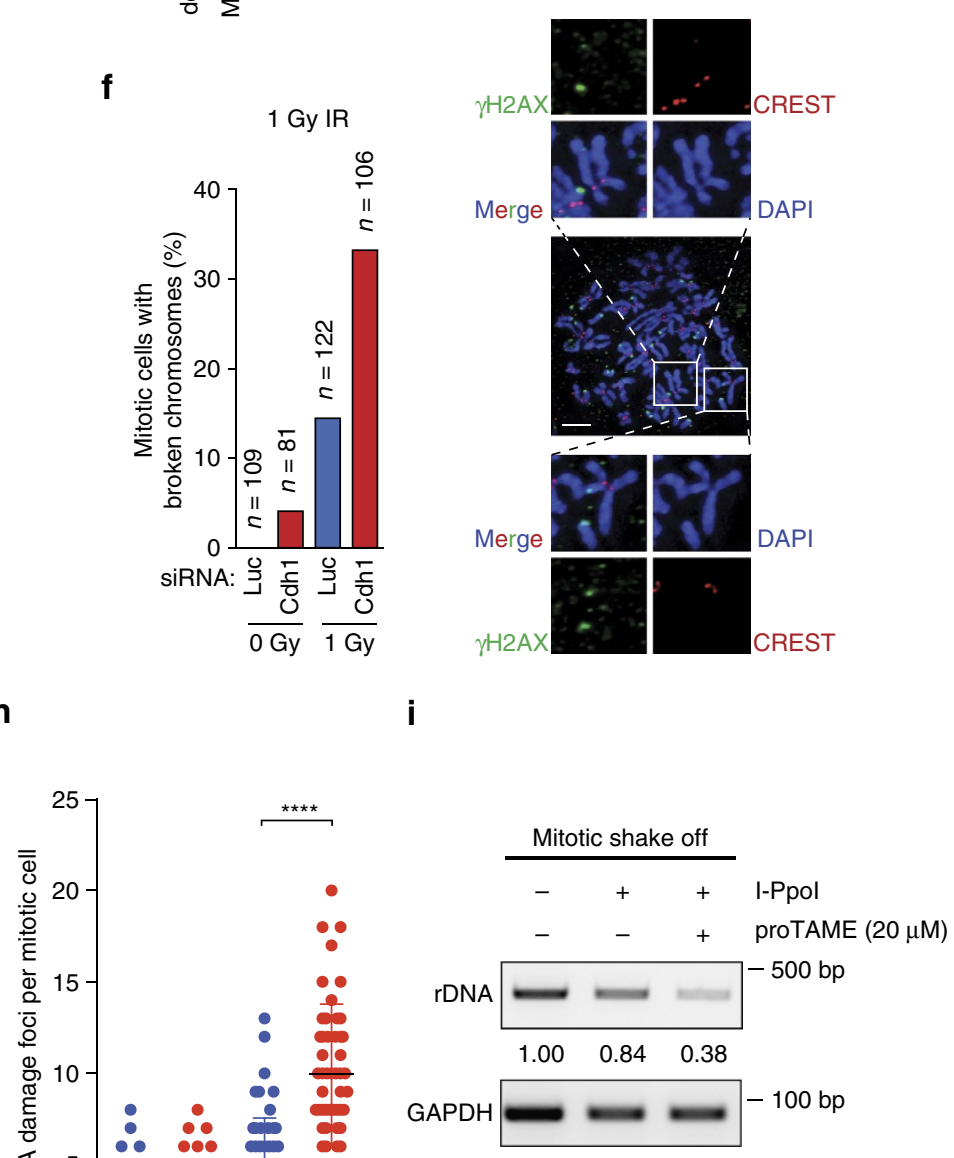

$\sum_{0}$

Wee1 inh: $\frac{-+}{0 \text { Gy }} \frac{-+}{0.5 \text { Gy }}$

\section{i}


We therefore hypothesized that rapid cell cycle exit of cells damaged in antephase would be especially important after low levels of damage, since these cells will likely progress into mitosis as soon as Cdk activity is restored. In such cases, the little time available for repair could pose a serious threat to genomic integrity, and this could be compensated by a rapid cell cycle exit to prevent cell division with broken chromosomes. Since, we could prevent the DNA-damage-induced Cyclin B1 degradation in antephase cells by overexpression of Emil, we asked if this could promote mitotic entry. Indeed, we find that mitotic entry is restored in antephase cells expressing Emil (Fig. 4d; Supplementary Fig. 4a). Importantly, the increased mitotic entry of antephase cells is associated with increased reappearance of 53BP1 foci in G1 daughter cells (Fig. 4e), indicating that loss of the antephase-specific response to low levels of DNA damage results in carryover of damaged DNA to the daughter cells. Similarly, the number of mitotic cells with broken chromosomes observed in Cdh1-depleted cells after 1 Gy irradiation was twice that seen in control cells (Fig. 4f). This difference is not a consequence of altered damage signalling caused by Cdh1 depletion, since the number of breaks was similar in luciferase- and Cdh1-depleted cells that were pushed into mitosis by the addition of caffeine (Supplementary Fig. 4c). To further test the robustness of the hypersensitive response in antephase, we collected cells that entered mitosis following $0.5 \mathrm{~Gy}$ or mock irradiation, and quantified foci positive for phosphorylated H2AX $(\gamma \mathrm{H} 2 \mathrm{AX})$ and MDC1. Cells that entered mitosis following $0.5 \mathrm{~Gy}$ of irradiation displayed only a slight increase in DNA-damage-associated foci compared with undamaged cells. In contrast, cells that were irradiated and co-treated with a Weel inhibitor to prevent Cdk inhibition entered mitosis with a considerable higher number of DNAdamage-associated foci (Fig. 4g,h). Together, this shows that the hypersensitive DNA-damage response in antephase accurately prevents the mitotic progression of damaged cells. Finally, we used the I-PpoI nuclease to track DNA damage at specific loci. This nuclease cuts in the ribosomal DNA (rDNA) in addition to several other locations in the genome ${ }^{38}$. Using PCR primers flanking the rDNA break sites, we observed only a slight reduction in intact rDNA in mitotic cells that recovered spontaneously from the induced damage. In contrast, when the antephase response was acutely abrogated using the APC/C inhibitor proTAME, a marked loss of intact rDNA was detected in cells that entered mitosis, indicating that many of the cells entered mitosis with residual breaks (Fig. 4i; Supplementary Fig. $4 \mathrm{~b}, \mathrm{~d}$ ). In conclusion, this previously unidentified cell cycle exit mechanism in antephase is important to prevent cell division with broken chromosomes.

\section{Discussion}

The fate of a cell after DNA damage is a result of the complex interplay between DNA repair, checkpoint signalling and cell cycle progression. It is still largely unknown how cell fate after DNA damage is determined. Our data show that cells in antephase have a very unique, irreversible response to DNA double strand breaks that can be engaged by minimal amounts of damage. The definite irreversibility of the DNA-damage response in antephase cells is in sharp contrast to the reversible cell cycle arrests that act in other stages of the cell cycle ${ }^{3}$. This response has important consequences for the fate of damaged cells in antephase, since low levels of damage already lead to an irreversible cell cycle exit.

Both terms early prophase and antephase have been used to refer to cells at the G2/M transition ${ }^{13,39,40}$. The term antephase was defined as stage in late G2, before visible signs of DNA condensation. While we do see Ser10-phosphorylated histone H3 appear in these cells, we do not see any visible signs of DNA condensation. We show that the cells we refer to as being in antephase have started centrosome separation and stain positive for mitotic phosphorylation sites, indicating that they are well on their way to mitosis. It should be noted that the current definition of antephase only clarifies when antephase ends, namely at the start of visible DNA condensation. It does not define when antephase starts. Our data indicate that the start of centrosome separation and/or degradation of Emil could serve as good markers to define the onset of antephase.

Interestingly, early-prophase or -antephase cells were previously reported to revert back into an interphase-like state upon various stresses, but assumed to re-enter the cell cycle afterwards ${ }^{41-43}$. For instance, mitotic entry is delayed when cells were treated with microtubule poisons ${ }^{44}$. This fully reversible arrest was shown to be dependent on checkpoint with FHA and RING finger domains (CHFR) and p38 signalling, and defined as the antephase checkpoint ${ }^{40}$. The antephase response we describe here is fundamentally different from this previously described antephase checkpoint. We find that DNA double strand breaks induce an irreversible response when they occur in antephase. Importantly, we show that cells in antephase are hypersensitive to DNA damage, when compared with cells in earlier stages of G2 phase. Moreover, our results reveal the underlying mechanism, and emphasize the importance of this response in protecting genomic integrity. We find that reinstalling reversibility of the DNA-damage response in antephase cells results in an increased carryover of DNA double strand breaks from mother to daughter cells.

In addition, we demonstrate an essential role for Emil in the DNA-damage checkpoint in G2 phase in that it acts to maintain

\footnotetext{
Figure 4 | Hypersensitivity in antephase protects genome stability. (a) Representative images from time-lapse movies of RPE CCNBYFP-53BP1 ${ }^{\mathrm{mCherry}}$ cells following 1 Gy IR. Stills are representative of three independent experiments. Star indicates tracked daughter cell after mitosis. Time, hh:mm. Scale bars, $10 \mu \mathrm{m}$. (b) Progression into a subsequent cell cycle scored in cells that had degraded Cyclin B1 after $1 \mathrm{~Gy}$ and cells that had recovered and entered mitosis. Rebuilding of Cyclin B1 expression within $72 \mathrm{~h}$ from IR was used to score cell cycle progression. Mean \pm s.d. of three independent experiments. (c) As in $\mathbf{a}$, except cells were followed for $144 \mathrm{~h}$ and then stained for SA- $\beta$-gal to identify senescent cells. Stills are representative of $n=16$ cells pooled from two experiments. Time, hh:mm. Scale bars, $10 \mu \mathrm{m}$. (d) Mitotic entry of antephase cells (selected as in Fig. 2a) in presence or absence of EMI1Tura overexpression. Mean \pm s.e.m. of three independent experiments. (e) Quantification of 53BP1 ${ }^{\mathrm{mCherry}}$ foci in $\mathrm{G} 1$ daughter cells $3 \mathrm{~h}$ after mitosis in the presence or absence of Emi1 overexpression, induced as in $\mathbf{d}$. $n=16$ (-Emi1 oe) and $n=29$ ( + Emi1 oe) number of cells analysed, pooled from three independent experiments. ${ }^{\star \star} P<0.01$ (unpaired $t$-test) (f). Quantification of mitotic cells with broken chromosomes in Luc- or Cdh1-depleted cells that entered mitosis within $4 \mathrm{~h}$ after IR. Average of $n$, number of cells analysed in two independent experiments. Representative images show broken (bottom) or intact (top) chromosomes. Scale bar, $5 \mu \mathrm{m}$. (g) Representative stills from mitotic cells following mock or $0.5 \mathrm{~Gy}$ IR stained for yH2AX and MDC1 to quantify double-positive DNA damage foci. Scale bars, $10 \mu \mathrm{m}$. (h) Number of double-positive foci per mitotic cell (as in $\mathbf{g}$ ). Wee1 inhibitor was added just after mock IR or 0.5 Gy. $n>100$ per sample pooled from three independent experiments. ${ }^{\star \star \star \star} P<0.0001$ (unpaired $t$-test). (i) PCR on genomic DNA from mitotic cells at the I-Ppol break site in the $45 \mathrm{~S}$ locus (rDNA) or GAPDH. Numbers indicate the quantification of rDNA band intensity normalized for DNA loading using the GAPDH control. (j) Model to show why cells in antephase are hypersensitive to DNA damage and how damaged antephase cells exit the cell cycle.
} 
checkpoint reversibility, thereby reducing sensitivity of a cell to DNA damage by allowing time for DNA repair and subsequent checkpoint recovery. As such, Emil could be particularly important for post-replication repair, needed to repair lesions that are created during replication in $S$ phase ${ }^{45,46}$. Thus, removal of cells that encounter DNA damage shortly before mitosis from the cell cycle is an important function of $\mathrm{APC} / \mathrm{C}^{\mathrm{Cdh} 1}$, and impairing this function could promote genomic instability. In this respect, it is of interest to note that both loss of Cdhl and overexpression of Emil have been reported in several tumour types ${ }^{21,26,47-49}$.

\section{Methods}

Time-lapse microscopy and irradiation. Cells were grown in Lab-Tek II chambered coverglass (Thermo Scientific) in Dulbecco's Modified Eagle Medium/ Nutrient Mixture F-12 (DMEM/F12), which was replaced by Leibovitz's L-15 (Gibco) $\mathrm{CO}_{2}$-independent medium just before imaging. Images were obtained using a DeltaVision Elite (applied precision) maintained at $37^{\circ} \mathrm{C}$ equipped with a $10 \times 0.4$ numerical aperture (NA) or $20 \times 0.75 \mathrm{NA}$ or $40 \times 1.35 \mathrm{NA}$ lens (Olympus) and cooled CoolSnap CCD camera. Only for time-lapse imaging of the RPE Fucci cells, cells were grown in 96-wells plate in DMEM/F12 during filming. Images were obtained using a CCD microscope (Zeiss AxioObserver.Z1 gemot.) maintained at $37^{\circ} \mathrm{C}$ and $5 \% \mathrm{CO} 2$ equipped with a $10 \times / 0.25$ Achroplan Ph1 lens and cooled Hamamatsu ORCA R2 Black and White CCD-camera. Image analysis was done using ImageJ software. Cells were $\gamma$-irradiated using a Gammacell Exactor (Best Theratronics) with a ${ }^{137} \mathrm{Cs}$ source.

\section{ImageJ macros for quantification of DNA-damage foci. Monitoring}

DNA-damage foci requires following individual cells over time. However, faithful automatic tracking of the highly motile RPE cells in densely covered samples proved to be unfeasible. Therefore, a hybrid approach was taken, where single cells were first manually isolated using an in-house developed cell tracking macro in ImageJ (NIH), after which the DNA damage response was fully automatically quantified with a second ImageJ macro. User-assisted tracking and segmentation of single cell (nuclei) is facilitated as follows: $Z$ stacks are converted to two dimensional using a maximum intensity projection. For every frame, a square region of defined size around the $x, y$ position of the mouse cursor is copied from the original three-dimensional/four-dimensional image stack into a new image stack. The size of the cropped square has to be chosen large enough to fully encompass the cell (nucleus) of interest, which is now centred in the newly generated movie. When holding down the mouse button the time series advances at a desired speed, allowing accurate manual tracking.

Single cell (nuclei) are isolated from such tracked-cell movies in the following manner: three-dimensional time-lapse movies are projected to two dimensional via one of several user-defined methods: maximum intensity projection, automatically select sharpest slice, manually select a slice or via a 'extended depth of field' algorithm.

Region of interests (ROIs) of candidate nuclei are automatically obtained throughout the image stack by auto-thresholding an outlier-removed median-filtered ( $0.7 \mu \mathrm{m}$ radius) $z$ projection of the nuclei channel, followed by a watershed command to separate touching nuclei and particle analyser run with size ( $>4$ and $<40 \mu \mathrm{m}^{2}$, and circularity $(>0.25)$ constraints. In each frame, the distances of all detected ROIs to the $x, y$ center of the image are calculated, after which all except the closest ROI are removed. This procedure thus yields a movie with a single ROI per frame, tightly surrounding the nucleus followed with the mouse in the manual tracking macro.

In the detection of DNA-damage foci, the foci threshold level is defined by the signal-to-noise ratio (SNR): a (user-set) factor times the s.d. of the background fluorescence intensity of the nucleus. The latter property is approximated by first crudely removing signal outliers (the foci), and then taking the median and s.d. of the lower $\sim 80 \%$ pixel values in the ROI, respectively. The background intensity is subtracted using a Difference of Gaussians filter. Foci are then identified as regions of adjacent pixels with grey values, exceeding the SNR threshold and area larger than a certain minimum. In the procedure, the SNR is the only user-defined parameter, and is iteratively optimized by comparing the detected foci with the original signal in an overlay image.

The evolution of the DNA-damage foci is quantified by reporting the number of foci, foci intensity, foci area, and the total signal above threshold for each time frame.

FACS-sort and SA- $\beta$-gal. Cells were trypsinized and resuspended in Leibovitz's L-15 medium for sorting, using a Becton Dickinson FacsAria Sorter or a Beckman Coulter Moflo Astrios. G2 cells were sorted based on Cyclin B1-YFP signal and replated for filming. RPE Fucci S phase cells were sorted based on Azami-Green and Kusabira-Orange double-positive signal, and replated for filming, fluorescenceactivated cell sorting (FACS) and western blot samples at indicated time points after the sort. For FACS analysis of Propidium Iodide (PI) profiles after the double- positive Fucci sort, cells were fixed in ice-cold ethanol at indicated time points after the sort. Cells were washed with $1 \times$ PBS before they were resuspended in $1 \times$ PBS + RNAse and PI (10 mM, Sigma). PI profiles were analysed using a Becton Dickinson FACSCalibur analyser. To detect SA- $\beta$-gal activity cells were fixed for 5 min using $2 \%$ formaldehyde $+0,2 \%$ gluteraldehyde in PBS within the Lab-Tek II chambered coverglass (Thermo Scientific) after 6 days of live-cell imaging. Cells were washed three times with $\times$ PBS before overnight $(16 \mathrm{~h})$ incubation in staining solution (X-gal in dimethylformamide $\left(1 \mathrm{mg} \mathrm{ml}^{-1}\right)$, citric acid/sodium phosphate buffer at pH6 $(40 \mathrm{mM})$, potassium ferrocyanide $(5 \mathrm{mM})$, potassium ferricyanide $(5 \mathrm{mM})$, sodium chloride $(150 \mathrm{mM})$ and magnesium chloride $(2 \mathrm{mM})$ ) at $37 \mathrm{C}$ (not in a CO2 incubator). Cells are washed with $1 \times \mathrm{PBS}$ and colour images to detect blue staining were taken using a CCD microscope equipped with a Zeiss AxioCam colour camera (Axiocam HRc).

Immunodetection and chemicals. For immune fluorescent staining, cells were fixed with $3 \%$ formaldehyde for $5 \mathrm{~min}$ and permeabilized with $0,2 \%$ TritonX for $5 \mathrm{~min}$ before blocking in $3 \%$ fetal bovine serum (BSA) in $1 \times$ PBS supplemented with $0,1 \%$ Tween (PBST) for $1 \mathrm{~h}$. Cells were incubated overnight at $4{ }^{\circ} \mathrm{C}$ with primary antibody in PBST with $3 \%$ BSA, washed three times with PBST, and incubated with secondary antibody and DAPI in PBST with 3\% BSA for $2 \mathrm{~h}$ at room temperature (RT). Immunofluorescent staining of Cyclin A, Aurora A and Plk1 was performed after formaldehyde fixation of cells that were tracked by live-cell imaging within the Lab-Tek II chambered coverglass (Thermo Scientific). Immunofluorescent staining of $\gamma \mathrm{H} 2 \mathrm{AX}$ and MDC1 DNA-damage foci was performed after formaldehyde fixation of mitotic cells that were collected $2 \mathrm{~h}$ after IR by shake-off. Nocodazole was added from $1 \mathrm{~h}$ after IR to entrap cells in mitosis and Weel inhibitor was added directly after IR where indicated.

For western blot analysis, equal amounts of proteins were separated by SDS-polyacrylamide gel electrophoresis electrophoresis followed by semi-dry transfer to a nitrocellulose membrane. Membranes were blocked in 5\% milk in PBST for $1 \mathrm{~h}$ at RT before overnight incubation with primary antibody in PBST with $3 \%$ BSA at $4{ }^{\circ} \mathrm{C}$. Membranes were washed three times with PBST followed by incubation with secondary antibody in PBST with $5 \%$ milk for $2 \mathrm{~h}$ at RT. Antibodies were visualized using enhanced chemiluminescence (ECL) (GE Healthcare). Uncropped western blot scans can be found in Supplementary Fig. 5.

The following primary antibodies were used in this study: anti-phospho- $\mathrm{H} 3$ (06-570 Upstate, 1/500), anti- $\gamma \mathrm{H} 2 \mathrm{AX}$ (ser139p; 05-636 Upstate, 1/500), anti-MPM2 (05-368 Ubi, 1/500), anti-MDC1 (ab11171 Abcam, 1/500), anti-Emil (376600 Novex, 1/500), anti-Cdh1 (DH01; ms 1116-p1 Neo, 1/500), anti-Cyclin B1 (GNS1; sc-245 Santa Cruz, 1/500), anti-Cdk4 (C-22; sc-260 Santa Cruz, 1/1,000), anti-HSP90 (sc7947 Santa Cruz, 1/1,000), anti-UBF (F-9; sc-13125 Santa Cruz, 1/500), anti-Cyclin A2 (H432; sc 751 Tebu, 1/1,000), anti-tubulin gamma (GTU-88; ab11316 Abcam, 1/1,000), anti-CREST serum (CS1058 Cortex Biochem, 1/1,000), anti-IAK1 (Aur A; 3092 Cell Signaling, 1/500), anti-GFP (homemade, gift from Geert Kops, 1/1,000), anti- $\gamma \mathrm{H} 2 \mathrm{AX}$ (2577 Cell Signaling, 1/500) and anti-BrdU (ab6326-250 Abcam, 1/500). The following secondary antibodies were used for western blot experiments: peroxidase-conjugated goat anti-rabbit (P448 DAKO, 1/1,000), goat anti-mouse (P0447 DAKO, 1/1,000) and rabbit anti-goat (P160 DAKO, 1/1,000). Secondary antibodies used for immunofluorescence and FACS analysis were goat anti-rabbit/Alexa 488 (A_11008 Molecular probes, 1/1,000), goat anti-mouse/Alexa 568 (A11004 Molecular probes, 1/1,000) and goat anti-rat/Alexa 647 (A21247 Molecular probes, 1/600)

Chemicals used in this study: RO-3306 (used at $5 \mu \mathrm{M}$ ) and Roscovotine (used at $25 \mu \mathrm{M}$; Calbiochem). Nocodazole (used at $250 \mu \mathrm{M}$ ), caffeine (used at $5 \mathrm{mM}$ ), doxocycline (used at $1 \mathrm{mM}$ ), Weel inhibitor MK-1775 (used at $3 \mu \mathrm{M}$ ), MG-132 (used at $5 \mu \mathrm{M}$ ) and Aphidicolin (used at 0.2 or $0.4 \mu \mathrm{M}$ ) were purchased at Sigma.

Cell lines. hTert-immortalized retinal pigment epithelium (RPE-1) cells (ATCC) were maintained in DMEM/F12 (Gibco) supplemented with ultraglutamine, antibiotics and $10 \%$ fetal calf serum. RPE- 1 cells in which a fluorescent tag was introduced in one allele of Cyclin B1 (RPE CCNB ${ }^{\mathrm{YFP}}$ ) have been described before ${ }^{15}$ HMEC-1 cells and MCF10a cells were maintained in DMEM/F12 (Gibco) supplemented with ultraglutamine, antibiotics, EGF $\left(20 \mathrm{ng} \mathrm{ml}^{-1}\right)$, hydrocortisone $\left(500 \mathrm{ng} \mathrm{ml}^{-1}\right)$ and insulin $\left(10 \mu \mathrm{g} \mathrm{ml}^{-1}\right)$. U2OS cells were maintained in DMEM (Gibco) supplemented with ultraglutamine, antibiotics and 6\% fetal calf serum. A fluorescent tag was introduced in one allele of Cyclin B1 $\left(C C N B^{\mathrm{YFP}}\right)$ in HMEC-1, MCF10a and U2OS cells AAV virus expressing a targeting sequence with $959 \mathrm{bp}$ homology upstream-eYFP- and 1,256 bp homology downstream in the CCNB gene was collected 2 days after transfection of HEK293 cells with pAAV-eYFP together with pRC and pHelper plasmids. Indicated cell types were infected with the targeting AAV virus and eYFP-positive cells were FACS sorted and plated to collect single-cell clones. Clones were selected based on correct eYFP expression on the centrosomes and degradation at the end of mitosis.

To make RPE1-Fucci cells HEK293 cells were transfected with Fucci constructs, which have been described before ${ }^{50}$ using X-tremeGENE (Roche) according to manufacturer's protocol. RPE-1 cells expressing ecotropic receptor, described before ${ }^{51}$, were infected after 2 days for $24 \mathrm{~h}$ and double-positive Fucci cells were sorted by FACS two weeks later.

The venus tag in the previously described CSII-EF-DHB-venus contruct ${ }^{23}$ was exchanged for mCherry to generate RPE CCNB1 ${ }^{\text {YFP }}$ DHB mCherry-expressing 
cells. HEK293 cells were transfected with CSII-EF-DHB-mCherry using

$\mathrm{X}$-tremeGENE (Roche) according to manufacturer's protocol. RPE CCNB1 ${ }^{\text {YFP }}$ cells were infected after 2 days for $24 \mathrm{~h}$ and mCherry-positive cells were sorted out by FACS 2 weeks later. RPE CCNB1 ${ }^{\text {YFP }}$-Turq-Emil cells were generated as described for the DHB-mCherry-expressing cells above, except that individual grown clones were selected to generate a monoclonal cell line. The venus tag in the previously described pT7-Venus-Emil construct ${ }^{29}$ (purchased from addgene, \#39854) was exchanged for mTurquoise. Subsequently, Cas9 was exchanged for mTurq-Emil in the all in one dox-inducible lentiviral pCW-Cas9 construct (purchased from addgene, \#50661), using Nhe1 and BamH1 restriction sites. RPE CCNB1 ${ }^{\mathrm{YFP}}$ 53BP1-mCherry and RPE CCNB1 ${ }^{\mathrm{YFP}}$ - Turq-Emi1- 53BP1-mCherry cells were generated using the 53BP1-mCherry construct described before ${ }^{52}$. Amphotropic Phoenix cells were transfected with 53BP1-mCherry using X-tremeGENE (Roche) and virus was used to generate 53BP1 mCherry-positive cells as described above. Positive cells were sorted out by FACS 2 weeks later. All cell lines described above were tested negative for mycoplasma contamination.

siRNA information. ON-TARGETplus SMARTpool siRNAs targeting luciferase (GL2 duplex), Cdh1/FZR1, Cdc20 and EMI1/FBXO5 were from Thermo Scientific, and were transfected using RNAiMAX (Life Technologies) according to the manufacturer's protocol. All transfections were performed $24 \mathrm{~h}$ before experiments.

Sample sizes. For all experiments where phenotypic outcome was quantified at least 50 cells per condition in each independent biological replicate were scored, $n \geq 50$. Exceptions are Fig. 1h. $n=6-27-$ Supplementary Fig. 1c. $n=31-52$ (RPE1), $n=18-41$ (U2OS), $n=5-40$ (MCF10a) and $n=21-45$ (HMEC) -Fig. 2a. $n=34-52-$ Fig. 2b. $n=6-15-$ Supplementary Fig. 2c. $n>38-$ Fig. 3b

$n=22-59$-Fig. 4 b. $n=18-22-$ Fig. 4 d. $n=19-49$-Supplementary Fig. $4 \mathrm{~b} n>32$.

Chromosome spreads. Luciferase or Cdh1-depleted RPE-1 cells were mock irradiated or irradiated with $1 \mathrm{~Gy}$ followed by nocodazole addition $1 \mathrm{~h}$ after IR to retain cells in mitosis, but exclude cells that were damaged in mitosis. Caffeine was added to control samples to push G2 cells into mitosis with double strand breaks (DSBs) as a positive control. Mitotic RPE-1 cells were collected by shake-off $4 \mathrm{~h}$ after IR, washed in $1 \times \mathrm{PBS}$ and treated for $25 \mathrm{~min}$ with $75 \mathrm{mM} \mathrm{KCl}$ at $37^{\circ} \mathrm{C}$. Cells were spun on coverslips at 1,800 r.p.m. for $5 \mathrm{~min}$ in a Cytospin 4 (Thermo Scientific). Cells were permeabilized for $1 \mathrm{~min}$ with PEM buffer (100 mM PIPES, $2 \mathrm{mM}$ EGTA, $1 \mathrm{mM}$ $\mathrm{MgSO}_{4}$; $\mathrm{pH} 6.8$ ) containing $0.25 \%$ Triton X-100 and then fixed for $10 \mathrm{~min}$ in $4 \%$ paraformaldehyde containing $0.1 \%$ Triton X-100. Fixed cells were washed three times in 1xPBS containing 0.1\% Tween-20 and then blocked for 30 min in PEM/3\% $\mathrm{BSA} / 0.1 \%$ Tween-20. Antibody incubations (ACA and $\gamma \mathrm{H} 2 \mathrm{AX}$ ) were performed overnight at $4{ }^{\circ} \mathrm{C}$. Cells were washed three times in $1 \times$ PBS containing $0.1 \%$ Tween20, and then incubated with secondary antibodies and $0.1 \mu \mathrm{g} \mathrm{ml}{ }^{-1}$ DAPI in PEM/ $3 \% \mathrm{BSA} / 0.1 \%$ Tween-20 for $2 \mathrm{~h}$ at RT. After three washing steps the coverslips were mounted on microscopic slides with Prolong Gold (Invitrogen) and stored at $4{ }^{\circ} \mathrm{C}$. DNA breaks were quantified based on DAPI and $\gamma \mathrm{H} 2 \mathrm{AX}$ signal in chromosome spreads.

I-Ppol and PCR. RPE-1 hTERT with doxycycline-inducible HA-FKBP(DD)-IPpoI were synchronized in late G2, using a double thymidine block followed $8 \mathrm{~h}$ release in the presence of doxycycline $\left(1 \mu \mathrm{g} \mathrm{ml}^{-1}\right)$. One hour before the addition of nocodazole $\left(250 \mathrm{ng} \mathrm{ml}^{-1}\right)$ to trap cells in mitosis, shield-1 $(0.5 \mu \mathrm{M})$ was added to stabilize the I-PpoI endonuclease. Four hours after the addition of nocodazole in the absence and presence of ProTame $(20 \mu \mathrm{M})$, cells were collected by a mitotic shake-off. Genomic DNA was extracted using DirectPCR-Cell (Viagen Biotech) according to the manufacturers protocol. PCR products were size-fractionated by gel electrophoresis and visualized by ethidium bromide staining. Primers used in this study:

rDNA (I-PpoI) forward: $5^{\prime}$-GCCTAGCAGCCGACTTAGAA-3'/reverse:

5'-CTCACCGGGTCAGTGAAAAA-3

GAPDH forward: $5^{\prime}$-TCGGTTCTTGCCTCTTGTC-3'/reverse:

$5^{\prime}$-CTTCCATTCTGTCTTCCACTC-3'

Data availability. The authors declare that all data supporting the findings of this study are available within the article and its Supplementary Information Files.

\section{References}

1. Jackson, S. P. \& Bartek, J. The DNA-damage response in human biology and disease. Nature 461, 1071-1078 (2009).

2. Bartek, J. \& Lukas, J. DNA damage checkpoints: from initiation to recovery or adaptation. Curr. Opin. Cell Biol. 19, 238-245 (2007).

3. Shaltiel, I. A., Krenning, L., Bruinsma, W. \& Medema, R. H. The same, only different-DNA damage checkpoints and their reversal throughout the cell cycle. J. Cell Sci. 128, 607-620 (2015).

4. Kastan, M. B. \& Bartek, J. Cell-cycle checkpoints and cancer. Nature 432, 316-323 (2004)

5. Bunz, F. et al. Requirement for $\mathrm{p} 53$ and $\mathrm{p} 21$ to sustain G2 arrest after DNA damage. Science 282, 1497-1501 (1998).
6. Andreassen, P. R., Lacroix, F. B., Lohez, O. D. \& Margolis, R. L. Neither p21WAF1 nor 14-3-3sigma prevents G2 progression to mitotic catastrophe in human colon carcinoma cells after DNA damage, but p21WAF1 induces stable G1 arrest in resulting tetraploid cells. Cancer Res. 61, 7660-7668 (2001).

7. Krenning, L., Feringa, F. M., Shaltiel, I. A., van den Berg, J. \& Medema, R. H. Transient activation of p53 in G2 phase is sufficient to induce senescence. Mol. Cell 55, 59-72 (2014).

8. Johmura, Y. et al. Necessary and sufficient role for a mitosis skip in senescence induction. Mol. Cell 55, 73-84 (2014).

9. Müllers, E., Silva Cascales, H., Jaiswal, H., Saurin, A. T. \& Lindqvist, A. Nuclear translocation of Cyclin B1 marks the restriction point for terminal cell cycle exit in G2 phase. Cell Cycle 13, 2733-2743 (2014).

10. Mikhailov, A., Cole, R. W. \& Rieder, C. L. DNA damage during mitosis in human cells delays the metaphase/anaphase transition via the spindle-assembly checkpoint. Curr. Biol. 12, 1797-1806 (2002).

11. van Vugt, M. A. T. M. et al. A mitotic phosphorylation feedback network connects Cdk1, Plk1, 53BP1, and Chk2 to inactivate the G(2)/M DNA damage checkpoint. PLoS Biol. 8, e1000287 (2010).

12. Giunta, S., Belotserkovskaya, R. \& Jackson, S. P. DNA damage signaling in response to double-strand breaks during mitosis. J. Cell Biol. 190, 197-207 (2010).

13. Bullough, W. S. \& Johnson, M. The energy relations of mitotic activity in adult mouse epidermis. Proc. R. Soc. Lond. B Biol. Sci. 138, 562-575 (1951).

14. Pines, J. \& Rieder, C. L. Re-staging mitosis: a contemporary view of mitotic progression. Nat. Cell Biol. 3, E3-E6 (2001).

15. Shaltiel, I. A. et al. Distinct phosphatases antagonize the p53 response in different phases of the cell cycle. Proc. Natl Acad. Sci. USA 111, 7313-7318 (2014).

16. Akopyan, K. et al. Assessing kinetics from fixed cells reveals activation of the mitotic entry network at the S/G2 transition. Mol. Cell 53, 843-853 (2014).

17. Charrier-Savournin, F. B. et al. p21-Mediated nuclear retention of cyclin B1-Cdk1 in response to genotoxic stress. Mol. Biol. Cell 15, 3965-3976 (2004).

18. Sudo, T. et al. Activation of Cdh1-dependent APC is required for G1 cell cycle arrest and DNA damage-induced G2 checkpoint in vertebrate cells. EMBO J. 20, 6499-6508 (2001).

19. Wiebusch, L. \& Hagemeier, C. p53- and p21-dependent premature APC/ $\mathrm{C}$-Cdh1 activation in G2 is part of the long-term response to genotoxic stress. Oncogene 29, 3477-3489 (2010).

20. Lee, J., Kim, J. A., Barbier, V., Fotedar, A. \& Fotedar, R. DNA damage triggers p21WAF1-dependent Emil down-regulation that maintains G2 arrest. Mol. Biol. Cell 20, 1891-1902 (2009).

21. Bassermann, F. et al. The Cdc14B-Cdh1-Plk1 axis controls the G2 DNA-damage-response checkpoint. Cell 134, 256-267 (2008).

22. Sivakumar, S. \& Gorbsky, G. J. Spatiotemporal regulation of the anaphasepromoting complex in mitosis. Nat. Rev. Mol. Cell Biol. 16, 82-94 (2015).

23. Spencer, S. L. et al. The proliferation-quiescence decision is controlled by a bifurcation in CDK2 activity at mitotic exit. Cell 155, 369-383 (2013).

24. Morgan, D. O. Principles of CDK regulation. Nature 374, 131-134 (1995).

25. Reimann, J. D. et al. Emil is a mitotic regulator that interacts with Cdc20 and inhibits the anaphase promoting complex. Cell 105, 645-655 (2001).

26. Hsu, J. Y., Reimann, J. D. R., Sørensen, C. S., Lukas, J. \& Jackson, P. K. E2F-dependent accumulation of hEmil regulates $S$ phase entry by inhibiting APC(Cdh1). Nat. Cell Biol. 4, 358-366 (2002).

27. Hansen, D. V., Loktev, A. V., Ban, K. H. \& Jackson, P. K. Plk1 regulates activation of the anaphase promoting complex by phosphorylating and triggering SCFbetaTrCP-dependent destruction of the APC Inhibitor Emil. Mol. Biol. Cell 15, 5623-5634 (2004).

28. Moshe, Y., Boulaire, J., Pagano, M. \& Hershko, A. Role of Polo-like kinase in the degradation of early mitotic inhibitor 1 , a regulator of the anaphase promoting complex/cyclosome. Proc. Natl Acad. Sci. USA 101, 7937-7942 (2004).

29. Di Fiore, B. \& Pines, J. Emi1 is needed to couple DNA replication with mitosis but does not regulate activation of the mitotic APC/C. J. Cell Biol. 177, 425-437 (2007).

30. Moshe, Y., Bar-On, O., Ganoth, D. \& Hershko, A. Regulation of the action of early mitotic inhibitor 1 on the anaphase-promoting complex/cyclosome by cyclin-dependent kinases. J. Biol. Chem. 286, 16647-16657 (2011).

31. Margottin-Goguet, F. et al. Prophase destruction of Emil by the SCF(betaTrCP/Slimb) ubiquitin ligase activates the anaphase promoting complex to allow progression beyond prometaphase. Dev. Cell 4, 813-826 (2003).

32. den Elzen, N. \& Pines, J. Cyclin A is destroyed in prometaphase and can delay chromosome alignment and anaphase. J. Cell Biol. 153, 121-136 (2001).

33. Geley, S. et al. Anaphase-promoting complex/cyclosome-dependent proteolysis of human cyclin A starts at the beginning of mitosis and is not subject to the spindle assembly checkpoint. J. Cell Biol. 153, 137-148 (2001).

34. Wolthuis, R. et al. Cdc20 and Cks direct the spindle checkpoint-independent destruction of cyclin A. Mol. Cell 30, 290-302 (2008). 
35. Di Fiore, B. \& Pines, J. How cyclin A destruction escapes the spindle assembly checkpoint. J. Cell Biol. 190, 501-509 (2010).

36. Machida, Y. J. \& Dutta, A. The APC/C inhibitor, Emil, is essential for prevention of rereplication. Genes Dev. 21, 184-194 (2007).

37. Verschuren, E. W., Ban, K. H., Masek, M. A., Lehman, N. L. \& Jackson, P. K. Loss of Emil-dependent anaphase-promoting complex/cyclosome inhibition deregulates E2F target expression and elicits DNA damage-induced senescence. Mol. Cell. Biol. 27, 7955-7965 (2007).

38. Warmerdam, D. O., van den Berg, J. \& Medema, R. H. Breaks in the 45S rDNA Lead to Recombination-Mediated Loss of Repeats. Cell Rep. 14, 2519-2527 (2016).

39. Summers, M. K., Bothos, J. \& Halazonetis, T. D. The CHFR mitotic checkpoint protein delays cell cycle progression by excluding Cyclin B1 from the nucleus. Oncogene 24, 2589-2598 (2005).

40. Matsusaka, T. \& Pines, J. Chfr acts with the $\mathrm{p} 38$ stress kinases to block entry to mitosis in mammalian cells. J. Cell Biol. 166, 507-516 (2004).

41. Gaulden, M. E. \& Perry, R. P. Influence of the Nucleolus on Mitosis as Revealed by Ultraviolet Microbeam Irradiation. Proc. Natl Acad. Sci USA 44, 553-559 (1958).

42. Carlson, J. G. X-ray-induced prophase delay and reversion of selected cells in certain avian and mammalian tissues in culture. Radiat. Res. 37, 15-30 (1969).

43. Rieder, C. L. \& Cole, R. W. Entry into mitosis in vertebrate somatic cells is guarded by a chromosome damage checkpoint that reverses the cell cycle when triggered during early but not late prophase. J. Cell Biol. 142, 1013-1022 (1998).

44. Rieder, C. L. \& Cole, R. Microtubule disassembly delays the G2-M transition in vertebrates. Curr. Biol. 10, 1067-1070 (2000).

45. Karras, G. I. \& Jentsch, S. The RAD6 DNA damage tolerance pathway operates uncoupled from the replication fork and is functional beyond S phase. Cell 141, 255-267 (2010).

46. Daigaku, Y., Davies, A. A. \& Ulrich, H. D. Ubiquitin-dependent DNA damage bypass is separable from genome replication. Nature 465, 951-955 (2010).

47. García-Higuera, I. et al. Genomic stability and tumour suppression by the APC/C cofactor Cdh1. Nat. Cell Biol. 10, 802-811 (2008).

48. Wäsch, R., Robbins, J. A. \& Cross, F. R. The emerging role of APC/CCdh1 in controlling differentiation, genomic stability and tumor suppression. Oncogene 29, 1-10 (2010).

49. Vaidyanathan, S. et al. In vivo overexpression of Emil promotes chromosome instability and tumorigenesis. Oncogene doi:10.1038/onc.2016.94 (2016).

50. Sakaue-Sawano, A. et al. Visualizing spatiotemporal dynamics of multicellular cell-cycle progression. Cell 132, 487-498 (2008).

51. Haarhuis, J. H. I.. et al. WAPL-mediated removal of cohesin protects against segregation errors and aneuploidy. Curr. Biol. 23, 2071-2077 (2013).
52. Janssen, A., van der Burg, M., Szuhai, K., Kops, G. J. P. L. \& Medema, R. H. Chromosome segregation errors as a cause of DNA damage and structural chromosome aberrations. Science 333, 1895-1898 (2011).

\section{Acknowledgements}

The research was funded by the Dutch Cancer Foundation (KWF; NKI 2014-6787), the Netherlands Organisation for Scientific Research (NWO) (022.001.003) and Top-Go ZonMw (91210065). We thank all Medema, Rowland and Jacobs lab members for the helpful discussions on this study.

\section{Author contributions}

R.H.M., F.M.F. and L.K. conceived and designed the experiments, and analysed data. F.M.F. and L.K. performed the experiments. A.K. performed and analysed chromosome spreads. B.vd.B. designed the DNA-damage foci analysis macro. J.vd.B performed and analysed the I-PPOI nuclease experiment. F.M.F. and R.H.M. wrote the manuscript.

\section{Additional information}

Supplementary Information accompanies this paper at http://www.nature.com/ naturecommunications

Competing financial interests: The authors declare no competing financial interests.

Reprints and permission information is available online at http://npg.nature.com/ reprintsandpermissions/

How to cite this article: Feringa, F. M. et al. Hypersensitivity to DNA damage in antephase as a safeguard for genome stability. Nat. Commun. 7:12618 doi: $10.1038 /$ ncomms12618 (2016)

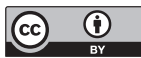

This work is licensed under a Creative Commons Attribution 4.0 International License. The images or other third party material in this article are included in the article's Creative Commons license, unless indicated otherwise in the credit line; if the material is not included under the Creative Commons license, users will need to obtain permission from the license holder to reproduce the material. To view a copy of this license, visit http://creativecommons.org/licenses/by/4.0/

(C) The Author(s) 2016 